\title{
Size-specific maternal effects in response to predator cues in an intertidal snail
}

\author{
D. B. Schwab, J. D. Allen* \\ College of William and Mary, Williamsburg, Virginia 23187-8795, USA
}

\begin{abstract}
The role of phenotypic plasticity in the adaptation of natural populations is a key issue in evolutionary ecology. Maternal effects are one source of plasticity in early development, and refer to the role of the maternal phenotype in generating offspring phenotypes. Reproductive investment, often a function of maternal size, is one mechanism for transmitting maternal effects. However, it is unclear how maternal size interacts with other ecological factors, such as predation pressure, to influence female reproductive behavior and offspring phenotype. We investigated how reproduction is influenced by maternal size in the presence of predators by exposing large and small adult mud snails Ilyanassa obsoleta to waterborne cues from the predatory green crab Carcinus maenas and the non-predatory green sea urchin Strongylocentrotus droebachiensis and measuring reproductive output (i.e. egg size and number, egg capsule number), egg capsule morphology, and offspring time to and size at hatching. Large snails produced more eggs overall than small snails, but the presence of green crabs did not affect reproductive output for either size class. Unexpectedly, small snails laid fewer capsules in the presence of green sea urchins. In contrast, capsule spine length increased in the presence of green crabs but was unaffected by the presence of sea urchins. Larval size at hatching significantly increased in the presence of both crabs and urchins. We also demonstrated the effectiveness of spines in deterring predatory crabs in the lab, and that snails are distributed in a manner consistent with the avoidance of green crab predators in the field. Maternal effects in I. obsoleta, therefore, appear to be size- and context-dependent, play an important role in defending embryos from predators, and are induced by cues from multiple members of the benthic community, including both crabs and urchins.
\end{abstract}

KEY WORDS: Maternal effects · Phenotypic plasticity $\cdot$ Predator-prey interactions $\cdot$ Gastropods

\section{INTRODUCTION}

Phenotypic plasticity provides organisms with the potential to respond adaptively to an array of environmental challenges, including predation, competition, and climate change (e.g. Trussell \& Smith 2000, Callaway et al. 2003, Charmantier et al. 2008). Early in ontogeny, plastic responses to environmental changes are frequently mediated by maternal effects, a term describing the causal role of maternal phenotype in shaping offspring phenotype (Bernardo 1996, Wolf \& Wade 2009). Maternal effects allow mothers to modulate offspring phenotype and, through the pro- cess of development, form a link between the environment experienced by one generation and the phenotype produced in the subsequent generation (Agrawal et al. 1999, Marshall 2008).

Maternal size has been shown to influence maternal effects when size directly influences offspring development through changes in maternal investment (Marshall \& Keough 2004a). For example, in the colonial bryozoan Bugula neritina, the size of the maternal colony is positively correlated with the size of that colony's larvae (Marshall \& Keough 2004b). In $B$. neritina and other marine invertebrate species, larger offspring size can influence a number of life 
history parameters, including time to and size at settlement, post-settlement survival and growth rate, and time to first reproduction (Marshall \& Keough 2003).

Although maternal size effects on reproduction and development are well documented across a number of taxa (e.g. insects: Corkum et al. 1997, fish: Rollinson \& Hutchings 2011, mammals: Pomeroy et al. 1999), there are fewer studies documenting the effect of maternal size on the responses of mothers or their offspring to ecological challenges such as predation risk. The few studies that have tested for these effects have failed to find a relationship between maternal size and offspring response to predators (e.g. Banks \& Powell 2004), except in species that lack parental care (Tollrian 1995). Marine invertebrates, the majority of whom develop in the absence of parental care, may be particularly likely to express maternal effects as a way to prepare offspring for an ecologically challenging environment as relatively unprotected embryos, larvae, and juveniles.

Whether maternal effects directly benefit offspring and may be adaptive, or are merely a byproduct of maternal responses to environmental changes, is unclear, and much work remains to be done to connect the life-history stages of marine invertebrates (Marshall \& Morgan 2011). In support of the potential adaptive value of maternal effects, latent effects or carry-over effects between life history stages are increasingly recognized across a wide variety of marine invertebrate taxa (Pechenik et al. 1998, Pechenik 2006). These effects include both traditional maternal effects and very recently even paternal effects revealed by interactions between the sperm environment and offspring phenotype (Ritchie \& Marshall 2013). Transgenerational maternal effects (e.g. Agrawal et al. 1999) are likely to be especially common in situations where the environment experienced by the mother is indicative of the environment experienced by her offspring (Uller 2008). Maternal production of offspring phenotypes that increase fitness under heterogeneous environmental conditions have been termed anticipatory maternal effects or AMEs (Marshall \& Uller 2007). AMEs in response to predator cues have been reported for both terrestrial and aquatic invertebrates (e.g. Storm \& Lima 2010). For marine invertebrates with highly dispersive larvae, AMEs may be unlikely to occur as the larval environment is unlikely to correlate with the maternal environment. However, for marine invertebrates with benthic development in egg capsules (e.g. gastropods, polychaetes, flatworms, and nemerteans), AMEs should be more likely as the maternal environment is very similar, if not identical, to the environment experienced by offspring developing in capsules. Here, we use Ilyanassa obsoleta, a gastropod with benthic development in egg capsules, as a model system for testing the effects of predator cues on maternal investment.

Ilyanassa obsoleta is an intertidal gastropod inhabiting mudflats from the Gulf of St. Lawrence to northern Mexico (Gosner 1978). Across this range, I. obsoleta can be found at high abundance, with up to 1000 adults $\mathrm{m}^{-2}$ (Fell et al. 1982, Cranford 1988). Reproductive adults of this species show significant size variation between the smallest $(\sim 14 \mathrm{~mm})$ and largest ( 26 mm) snails (Scheltema 1962, D. B. Schwab \& J. D. Allen unpubl. data). During the reproductive season, I. obsoleta primarily deposit egg capsules containing between 30 and 300 eggs on blades of eelgrass (Brenchley 1982, Rittschof et al. 2002). Embryos develop inside capsules with no parental care for approximately $2 \mathrm{wk}$, at which point larvae secrete a hatching enzyme that allows them to exit the egg capsule through the capsule plug (Pechenik 1975, Sullivan \& Bonar 1984). Hatchlings then disperse as obligately feeding veliger larvae for 2 to $8 \mathrm{wk}$ before settling on the benthos as juvenile snails (Scheltema 1961, Scheltema 1962, Brenchley 1982).

During encapsulation, Ilyanassa obsoleta is known to be preyed upon by green crabs Carcinus maenas, hermit crabs Pagurus longicarpus, and periwinkles Littorina littorea (Brenchley 1982). With no parental care, encapsulated eggs, embryos, and larvae are expected to be highly susceptible to these and other benthic predators (Allen \& McAlister 2007). Yet, mud snails persist and thrive in intertidal mudflat communities, even competitively displacing native species in areas where they are introduced (Race 1982). While phenotypic plasticity of adult gastropods in response to crustacean predators has frequently been demonstrated (e.g. Appleton \& Palmer 1988, Trussell 1996), only rarely have the effects of predators on reproductive plasticity been examined (Rawlings 1990), and rarer still are studies examining how predator presence and maternal size interact with one another (Tollrian 1995). It may, therefore, be instructive to study the range of plastic responses and adaptations that allow mud snails to mitigate the threat of predation during their life cycle.

To test the effects of maternal size, predator presence, and their interaction on reproductive plasticity, we exposed adult mud snails of 2 size classes to cues from the predatory crab Carcinus maenas and the green sea urchin Strongylocentrotus droebachiensis, 
which was intended as a metabolic control, in a laboratory setting. We then tested the response of these snails to the presence of crab and urchin cues by measuring reproductive parameters including egg size, egg number, capsule morphology (height, width, and spine length), larval size-at and time-to hatching. We then examined the intertidal distribution of adult mud snails in order to observe whether their distribution in the field is consistent with the avoidance of predators. Finally, based on the results of laboratory predation trials with the hermit crab Pagurus longicarpus, we measured the spine lengths of field-collected egg capsules to test whether egg capsules appear to suffer selective predation related to spine length.

We predicted that reproductive output (capsule number, egg number, and egg size) would increase with female size, as has been shown in other gastropod species (e.g. Spight \& Emlen 1976, Chatzinikolaou \& Richardson 2010). In the presence of benthic predators, adult Ilyanassa obsoleta of all sizes were predicted to lay smaller eggs. Smaller eggs were predicted to result in reduced time to hatching, based on the positive correlation between egg size and time to hatching known from comparative studies of gastropods (Perron 1981a). Reduced hatching time was predicted as a mechanism to facilitate dispersal of developing stages away from benthic predators and into the relative safety of the water column (Allen \& McAlister 2007, Vaughn \& Allen 2010). Smaller egg sizes and shorter hatching times were predicted to result in a smaller size at hatching. We also predicted that, in the presence of predators, snails of all sizes would increase the length of the protective spines surrounding the capsule plug, in order to deter capsule entry. Confirmation of this hypothesis led us to directly test the efficacy of increased spine length in deterring hermit crab predation, with the prediction that longer-spined capsules would have higher survival. Interactions between maternal size and responses to predator presence were expected to occur and, in particular, we expected smaller females to reduce their reproductive output. Reduced reproductive output was predicted as a consequence of shifting available resources away from reproduction and towards morphological or behavioral defenses in order to deter predation.

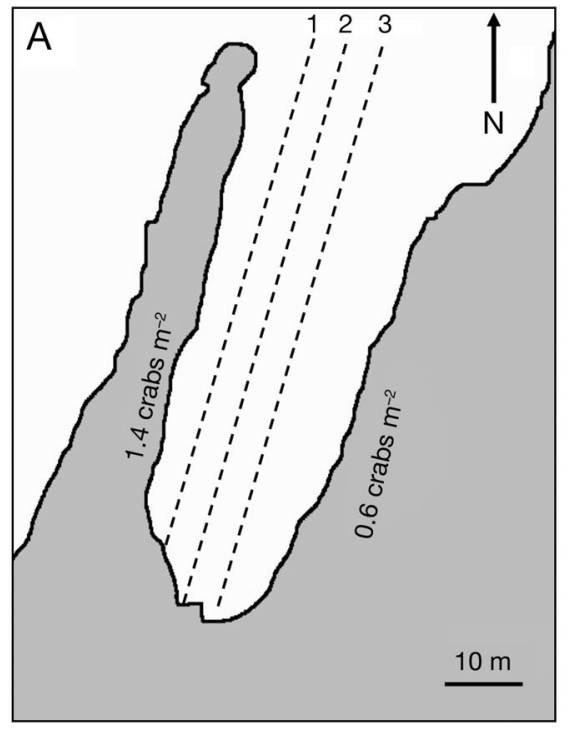

Fig. 1. (A) Map of field collection site on Orr's Island, Harpswell, ME, USA. Transects (1-3) are drawn on the map in their approximate orientation and location along the shoreline. Gray areas represent edge of rocky shore bordering the mudflat in white. (B) Density, (C) mean size, and (D) biomass of mud snails found along transects $1-3$, plotted against the height $(\mathrm{m})$ below the high tide line

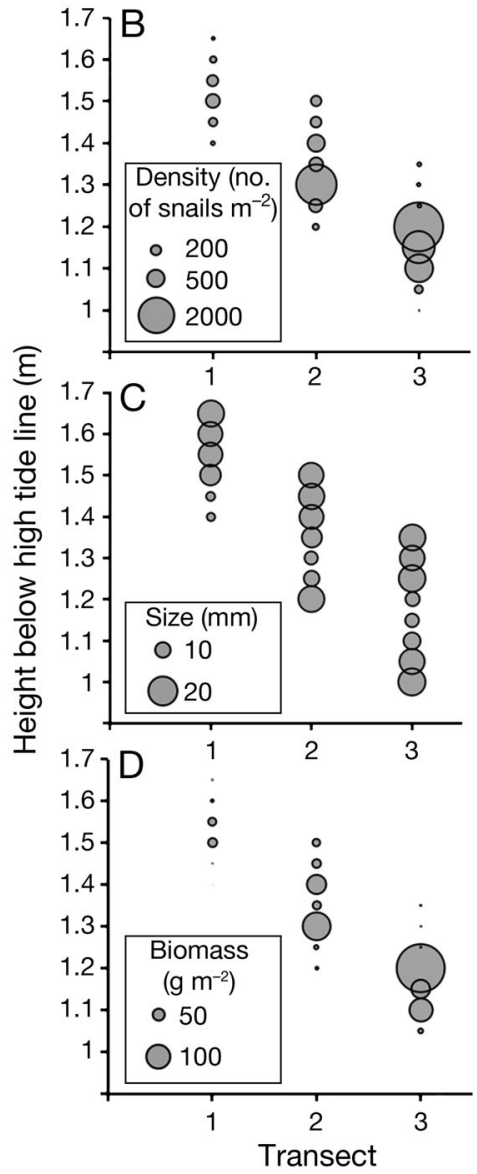

\section{MATERIALS AND METHODS}

\section{Field studies of intertidal distribution}

All laboratory experiments were conducted at the Bowdoin College Coastal Studies Center (CSC) on Orr's Island, Maine, USA, and all field collections of adult snails and egg capsules were made at the CSC on a nearby mudflat $\left(43^{\circ} 47^{\prime} 23^{\prime \prime} \mathrm{N}, 69^{\circ} 57^{\prime}\right.$ $\left.33^{\prime \prime} \mathrm{W}\right)$. To assess spatial distribution and size-based demography of the mud snail population, 3 equidistant transects were laid across the mudflat and numbered from 1 to 3 in an eastward progression (Fig. 1). The width of the mudflat at the low tide line was $42.5 \mathrm{~m}$ and the mudflat was bordered on either side by rocky shore covered with fucoid algae. Ilyanassa obsoleta along each transect were counted, sexed, and measured (shell length from aperture lip to apex), from the high to the low tide line using continuous $1 \mathrm{~m}^{2}$ quadrats. The vertical differ- 
ence between the high and low tide lines was $1.7 \mathrm{~m}$, and the vertical and horizontal location of each quadrat along this gradient was recorded. Because a given horizontal distance along transects was not always at the equivalent tidal height, we plotted our data on snail distributions with respect to vertical drops in tidal height (Fig. 1). If a small number of snails $(<100)$ were contained within a quadrat, all snails within that quadrat were collected and measured for shell length and destructively sampled for sex ratio determination (see 'Laboratory studies ...' below). Quadrats containing $>100$ snails were subsampled using a $0.25 \mathrm{~m}^{2}$ quadrat placed haphazardly within the $1 \mathrm{~m}^{2}$ quadrat. All snails within the $0.25 \mathrm{~m}^{2}$ quadrat were collected, measured, and destructively sampled for sex ratio determination.

Because green crabs Carcinus maenas are a common predator of mud snails and their egg capsules, we hypothesized that the density of crabs could potentially influence the spatial distribution of mud snails. In order to test this hypothesis, green crab density was sampled beneath the fucoid algal canopy covering the rocky shoreline near the borders of transects 1 and 3 (Fig. 1). Ten replicate $1 \mathrm{~m}^{2}$ quadrats were placed haphazardly along the eastern and western borders of the study site, and all green crabs with a carapace width $\geq 25 \mathrm{~mm}$ were counted.

\section{Laboratory studies of reproductive investment and development}

In order to assess how reproductive output varied with snail size and predator cue, adult Ilyanassa obsoleta were hand-collected on June 13, 2011 from the CSC mudflat and maintained in flow-through seawater tanks throughout the duration of the experiment. On June 15, 2011, 600 adult snails were divided evenly on the basis of shell length into small (15-19 $\mathrm{mm})$ and large $(21-25 \mathrm{~mm})$ size classes, and sorted randomly into 1 of 15 replicate flow-through plastic containers $(23.2 \mathrm{~cm}$ length $[\mathrm{L}] \times 16.8 \mathrm{~cm}$ width $[\mathrm{W}] \times 8.9 \mathrm{~cm}$ height $[\mathrm{H}]$ ), for a total of 30 containers housing 20 snails each. Each container was asymmetrically divided by a mesh insert up which snails preferentially crawled (insert size: $1 \mathrm{~cm}$ thick $\times 15.0 \mathrm{~cm}$ $\mathrm{W} \times 8.5 \mathrm{~cm} \mathrm{H}_{\text {; }}$ square pore size: $1.06 \mathrm{~mm}^{2}$ ), with snails contained in the larger section $(14.75 \mathrm{~cm} \mathrm{~L} \times$ $16.8 \mathrm{~cm} \mathrm{~W} \times 8.9 \mathrm{~cm} \mathrm{H}$ ) and cue organisms contained in the smaller section $(7.0 \mathrm{~cm} \mathrm{~L} \times 16.8 \mathrm{~cm} \mathrm{~W} \times 8.9 \mathrm{~cm}$ $\mathrm{H})$. For each size class, there were 5 replicate containers for each of the 3 cue types: (1) predator: the green crab Carcinus maenas, 26-37 g; (2) a meta- bolic control to ensure snail responses were not simply due to the presence of any heterospecific cue: the green sea urchin Strongylocentrotus droebachienis, 25-34 g; and (3) a control containing no organism in the smaller section, in which only ambient (background) cues were present. Both large and small sections in experimental and control groups received one freshly crushed blue mussel Mytilus edulis twice per week as a food source. Uneaten mussels were removed at each feeding.

On each day of the experiment, the mesh insert was removed and the number of egg capsules were counted in order to investigate the total number of, and day on which, egg capsules were laid. To assess egg number per capsule and egg size, 10 freshly-laid egg capsules were haphazardly removed from the mesh of each replicate and examined under a dissecting microscope at $10 \times$ magnification. The top of each egg capsule was removed using a razor blade, and eggs were gently pushed out of the capsule onto a glass slide using forceps. Slides were then moved to a compound microscope where eggs were counted at $100 \times$ and measured at $250 \times$ magnification.

To assess the size of the egg capsules, 30 capsules of each replicate were removed at approximately $5 \mathrm{~d}$ post-laying and measured for capsule height, capsule width, and spine length using the ocular micrometer of a dissecting scope at $10 \times$ magnification (Fig. 2).

To assess time to hatching, egg capsule deposition and larval hatching were tracked throughout the duration of the experiment. The average time to larval hatching was determined by the difference between the time when $50 \%$ of capsules were laid and the time when $50 \%$ of capsules were hatched. Egg capsules were removed via forceps following hatching and counted as part of a final egg capsule tally for each container. Capsules were visually scored as hatched when no embryos were seen inside of them.

To assess size at hatching, 5 capsules from each replicate were selected haphazardly just prior to hatching and placed into individual wells within a plastic 6 -well plate. Following hatching, larvae were immediately concentrated and then transferred to $1.7 \mathrm{ml}$ microcentrifuge tubes and preserved in $70 \%$ ethanol in $0.45 \mu \mathrm{m}$ filtered seawater. Fixed larvae were then transported from the CSC to the College of William and Mary in Virginia for measurement. The shell length of each veliger larva was measured using a Zeiss Achromat S Stereomicroscope to assess size at hatching.

Data collection began when the first egg capsules were laid, on June 20, 2011, 5 d after adult Ilyanassa 


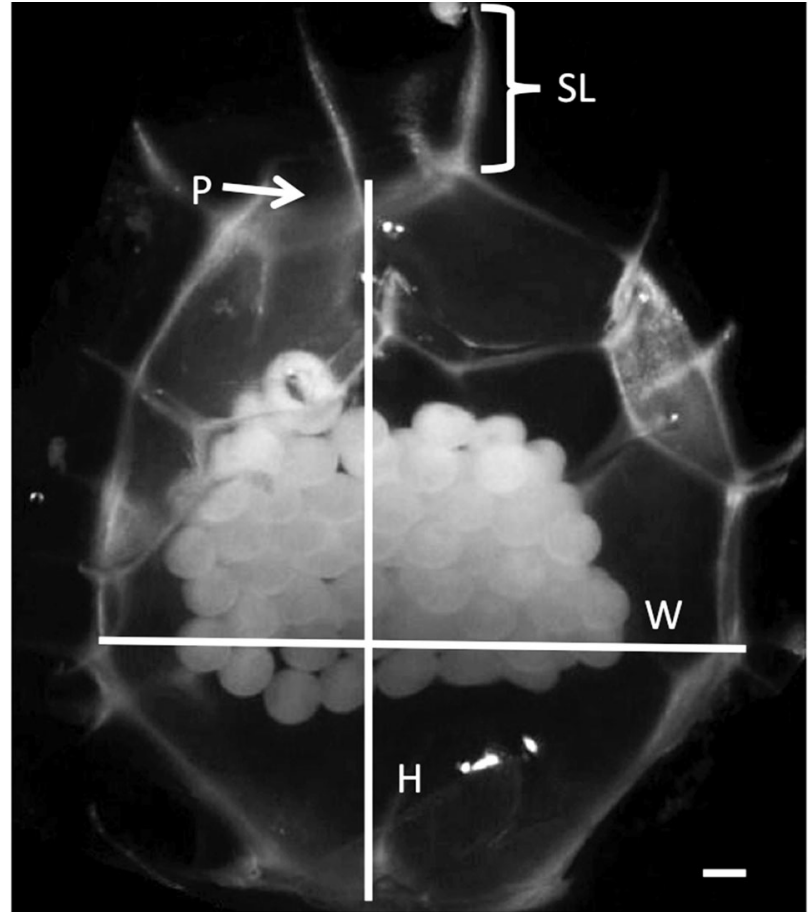

Fig. 2. Metrics for capsule morphology analysis. (H) Capsule height was measured as the longest distance from the capsule base to the top of the (P) capsule plug. (W) Capsule width was defined as the widest part of the capsule perpendicular to H. Spine length (SL) was defined as the length of the longest capsule spine, measured from the capsule wall to the tip of the spine. Scale bar $=100 \mu \mathrm{m}$

obsoleta were deposited in each container and exposed to cues. The experiment was terminated for each container after the final capsule had hatched, on August 7, 2011, at which point adult I. obsoleta were destructively sampled by crushing their shell with a C-clamp. Snail sex is cryptic in I. obsoleta and direct observation of gonad color is the most reliable way to determine the sex of a snail. Crushing the shell made it possible to determine the sex ratio in each replicate and obtain an accurate measure of maternal investment per female. Snails were scored as male if their gonad was dark-orange or red in color and as female if the gonad was a cream to lightorange color (Curtis 1997).

We conducted 2-way analyses of variance (ANOVA) for the following dependent variables: egg capsule number, egg number per capsule, total reproductive output (i.e. egg number multiplied by egg capsule number), egg size, capsule morphometrics, and larval time to and size at hatching. In each ANOVA, adult snail size (large or small) and cue type (green crab, urchin, control) and the interaction between size and cue type were modeled as fixed effects. For the ANOVAs, testing these fixed effects on reproductive output and egg capsule morphometrics, where dependent variables are not likely to be independent, we adjusted our original alpha value (0.05) downward using a Bonferroni correction. When there was a significant effect of cue type, we conducted Bonferroni post-hoc tests to analyze differences among treatment levels. Prior to ANOVA, the distributions of all dependent variables were tested for normality using a Kolmogorov-Smirnov test. All statistical analyses were completed using SPSS statistical software, version 18.

\section{Predation trials}

To test whether capsule spines deter predation, 10 short-spined (0-375 $\mu \mathrm{m}$ spine length [SL]) and 10 long-spined (>575 $\mu \mathrm{m}$ SL) egg capsules were selected and, using a random number generator, glued randomly to each of 20 adjacent positions on a blade of eelgrass Zostera marina using Krazy Glue ${ }^{\mathrm{TM}}$ gel. In previous studies, the glue was found to effectively cement the egg capsules of a variety of marine invertebrates without deterring predators or compromising embryonic development (J. D. Allen pers. obs.). Each piece of eelgrass was isolated in a plastic container housing either 1 hermit crab Pagurus longicarpus $(\mathrm{n}=10), 1$ green crab Carcinus maenas $(\mathrm{n}=3)$, or 1 green sea urchin Strongylocentrotus droebachiensis $(\mathrm{n}=3)$. Potential predators were allowed to feed on egg capsules until approximately $50 \%$ were consumed or until $24 \mathrm{~h}$ had elapsed since the beginning of the trial, at which point the individual predator was replaced if it had not begun feeding. Due to variability in individual crab feeding behavior, it was often difficult to stop hermit crab feeding when exactly $50 \%$ of capsules had been consumed. Often, hermit crabs would exceed $50 \%$ capsule consumption due to rapid feeding, or, conversely, would feed on several capsules but not reach $50 \%$ capsule consumption within $24 \mathrm{~h}$. Therefore, feeding trials were only included in our analysis if hermit crabs preyed upon $\geq 45 \%$ or $\leq 85 \%$ of capsules. We used a logistic regression in order to model predator preference for egg capsules using 5 predictor variables: trial number, position on the blade, capsule height, capsule width, and spine length. As part of the logistic regression, we used a HosmerLemeshow test in order to test the goodness of fit of the model.

Following the results of the laboratory predation trials, we conducted a field assessment of capsule 
morphologies. We hypothesized that if spines serve a defensive purpose, older capsules should have longer spines than younger capsules due to selective removal of short-spined capsules over time. To test this hypothesis, we haphazardly collected 30 egg capsules from each of 3 classes: capsules containing pre-veliger stage embryos, capsules containing unhatched veliger larvae, and empty capsules missing the capsule plug (Fig. 2) but with no other signs of damage (i.e. presumably capsules that successfully hatched). For each class (embryo, unhatched veliger, and hatched), we measured capsule height, capsule width, and capsule spine length (90 capsules total ${ }_{i}$ Fig. 2). Since these data were normally distributed (as determined by a KolmogorovSmirnov normality test), we analyzed them using a series of 1-way ANOVAs where capsule type was a fixed factor and each of the 3 morphometric measurements was a dependent variable. When significant differences among capsule types were found, Bonferroni corrected post-hoc tests were conducted as a means of testing the significance of multiple pair-wise comparisons.

\section{RESULTS}

\section{Intertidal distribution}

Snail density increased from west to east across the mudflat. Transect 3, the easternmost transect, contained the highest average density of snails (289 snails $\mathrm{m}^{-2}$ ), followed by transect 2 (177 snails $\mathrm{m}^{-2}$ ) and transect 1 (61 snail $\mathrm{m}^{-2}$; Fig. $1 \mathrm{~B}$ ). This frequency distribution of snails was significantly different from the null expectation of a uniform distribution $\left(\chi^{2}=5740 ; \mathrm{p}<0.0001\right)$. Conversely, average shell length increased from transect $3(9.3 \mathrm{~mm})$ to transect $2(12.3 \mathrm{~mm})$ to transect $1(15.2 \mathrm{~mm})$, but this increase was not significant (1-way ANOVA; $F_{2,18}=0.475 ; \mathrm{p}=0.629$ ). Within each transect, larger snails tended to be closer to the low tide line, with smaller snails aggregating near the middle of each transect (Fig. 1C). Snail size increased again near the upper part of the snail distribution in transects 2 and 3, driven by a small number of large individuals. During our survey of the rocky shores running parallel to our transects, we found that green crab density was highest near transect 1 (1.4 crabs $\left.\mathrm{m}^{-2}\right)$ and lowest near transect $3(0.6$ crabs $\mathrm{m}^{-2}$ ), suggesting that both the highest density of snails and the snails with the smallest shells were found in areas of relatively low green crab abundance. We also calculated the total biomass of snails found at each point along the transect, using an equation relating soft tissue mass to length that was derived using data from a pilot study (D. B. Schwab \& J. D. Allen unpubl. data) and based on established methods for estimating gastropod biomass (Palmer 1982, Trussell \& Smith 2000). This analysis revealed that biomass was greatest in transect $3\left(17.25 \pm 1.63[\mathrm{SE}] \mathrm{g} \mathrm{m}^{-2}\right)$, furthest from the area of high crab density. In contrast, transect 1 had the lowest biomass (14.73 $\pm 2.58 \mathrm{~g} \mathrm{~m}^{-2}$ ) and transect 2 had a biomass similar to transect $3\left(16.82 \pm 1.53 \mathrm{~g} \mathrm{~m}^{-2}\right.$; Fig. 1D). These across-transect differences in biomass were not, however, significantly different (1-way ANOVA; $F_{2,18}=1.025 ; \mathrm{p}=0.329$ ).

Snail sex was strongly correlated with snail size (Fig. 3). We used the curve estimation procedure in SPSS to assess the fit of several functions to our data and found that our data were best fit by a quadratic function (Adjusted $\mathrm{R}^{2}=0.799 ; \mathrm{p}<0.001$ ). Within smaller size classes (14-19 mm), $83.1 \%$ of all snails were males. In the larger size classes (20-25 mm), $76.9 \%$ of all snails were females. Between the 19 and $21 \mathrm{~mm}$ size classes, the percentage of males dropped dramatically from $77 \%$ to only $17 \%$. Because male snails tended to be smaller, they were most frequently found higher in the intertidal than females.

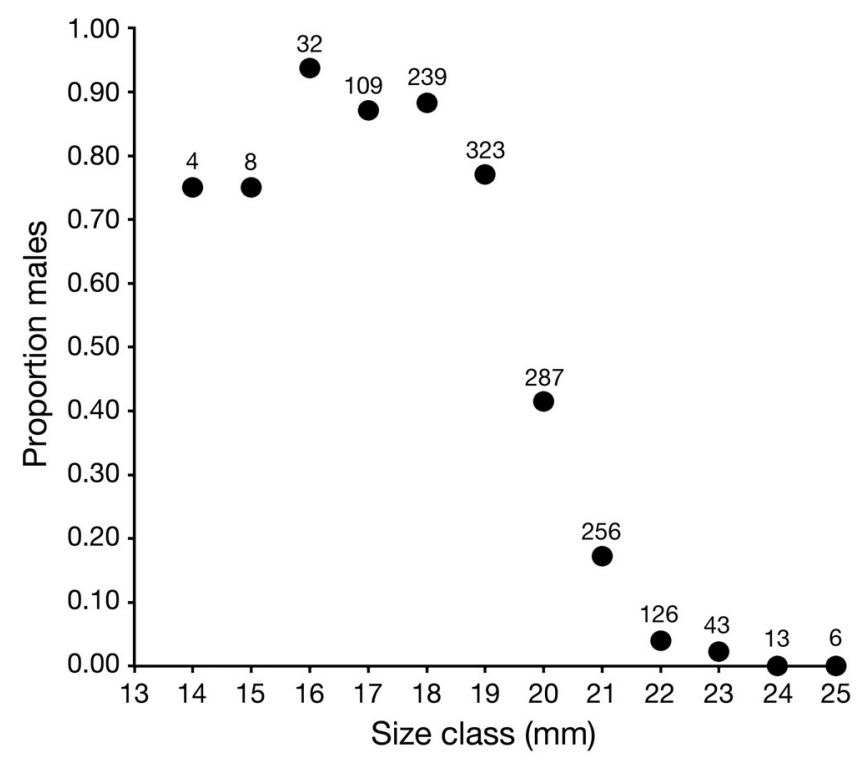

Fig. 3. Proportion of snails that are male plotted against shell length. The $14 \mathrm{~mm}$ size class includes all snails with a shell length from $14.01 \mathrm{~mm}$ to $15.00 \mathrm{~mm}$, the $15 \mathrm{~mm}$ size class includes all snails with a shell length from $15.01 \mathrm{~mm}$ to 16.00 , and so on for each size class. Numbers above points indicate the sample size of each size class 


\section{Reproductive investment and development}

There was no effect of cue type or snail size on the number of egg capsules that were laid (Table 1A). However, there was a significant interaction between snail size and cue type. This interaction was driven by the green sea urchin treatment, in which for small snails egg capsule production was suppressed relative to other treatments (Fig. 4A). Though they did not lay more egg capsules, large snails did deposit more eggs per capsule than small snails (Table 1B). There was no effect of cue type on this variable, nor was there an interactive effect between size and predator presence (Table 1B, Fig. 4B).

Assessing the total reproductive output of female Ilyanassa obsoleta revealed that large snails produced a significantly greater quantity of eggs during the reproductive season than small snails (Table 1C, Fig. 4C). Cue type was not a statistically significant effect ( $p=0.522$; Table $1 C)$, nor was there a significant interaction between size and cue type $(\mathrm{p}=$ 0.062). However, for small snails total reproductive output was suppressed by $70 \%$ in the presence of green sea urchins, compared to a $33 \%$ and $20 \%$ reduction in the presence of crab cue and controls respectively (Fig. $4 \mathrm{C}$ ).

We also tested whether egg size varied among treatments, and found that large snails produced eggs that were not significantly different in size from those produced by small snails (Table 2A, Fig. 5A). Additionally, there was no effect of maternal size on larval body length at hatching (Table 2B, Fig. 5B). However, larvae were significantly longer at hatching when exposed to a predator (Table 2B); in the presence of green crab cue, larvae had a significantly longer shell than controls (Bonferroni post hoc test;

Table 1. Two-way ANOVAs on reproductive characteristics. Snail size, cue type, and their interaction were modeled as fixed effects. Container was modeled as a random effect. Significant effects $(p<0.016)$ are listed in bold

\begin{tabular}{|cccrc|}
\hline \multirow{2}{*}{ Dependent variable } & Factor & df & \multicolumn{1}{c}{$F$} & $\mathrm{p}$ \\
\hline (A) Egg capsule & Size & 1,24 & 5.326 & 0.030 \\
number female & Cue & 2,24 & 0.805 & 0.459 \\
& Size $\times$ Cue & $\mathbf{2 , 2 4}$ & $\mathbf{5 . 1 0 3}$ & $\mathbf{0 . 0 1 4}$ \\
(B) Egg number & Size & $\mathbf{1 , 2 4}$ & $\mathbf{1 4 . 1 1 8}$ & $\mathbf{0 . 0 0 1}$ \\
& Cue & 2,24 & 0.449 & 0.643 \\
(C) Total eggs & Size $\times$ Cue & 2,24 & 1.470 & 0.250 \\
produced female & Size & $\mathbf{1 , 2 4}$ & $\mathbf{1 7 . 6 8 7}$ & $\mathbf{0 . 0 0 1}$ \\
& Cue & 2,24 & 0.668 & 0.522 \\
& Size $\times$ Cue & 2,24 & 3.121 & 0.062 \\
\hline
\end{tabular}
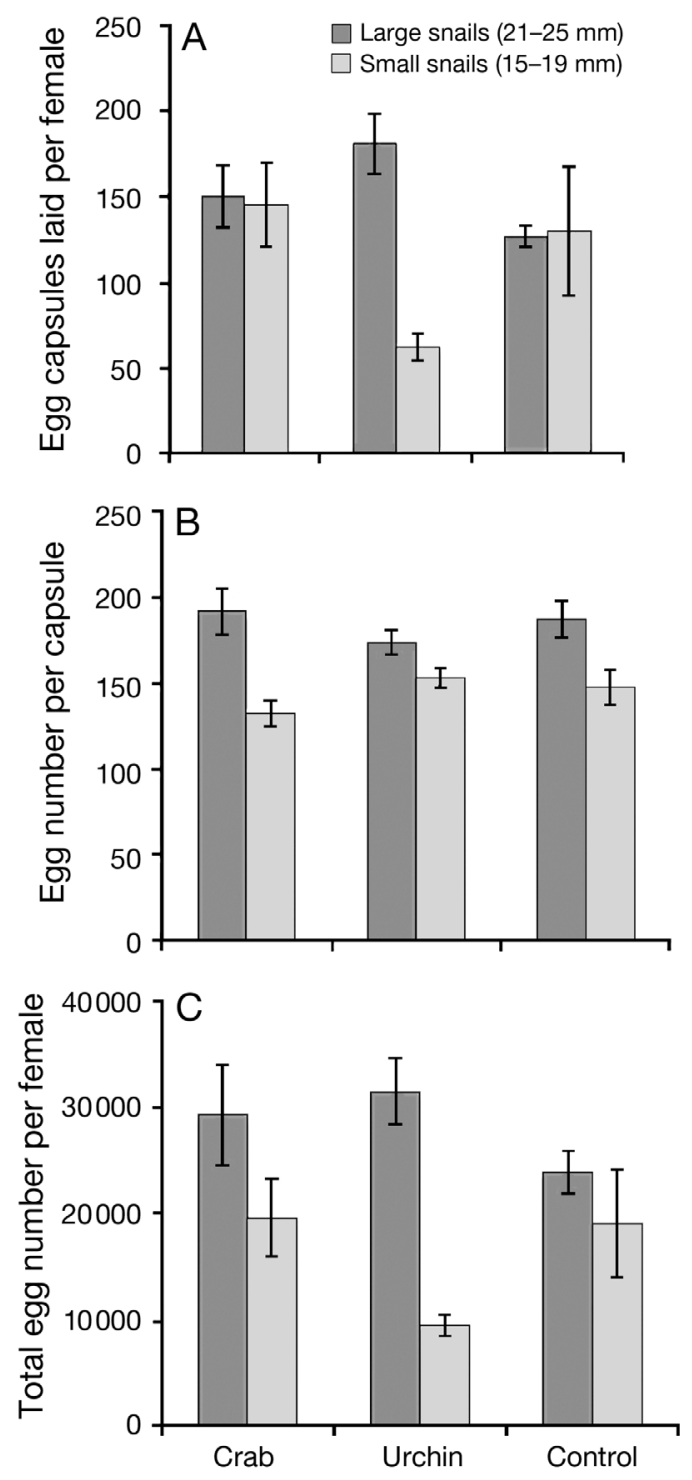

Fig. 4. Mud snail reproductive output versus cue treatment. (A) Number of egg capsules laid per female. (B) Number of eggs per capsule. (C) Total number of eggs produced per female. All bars represent means $\pm \mathrm{SE}$ for $\mathrm{N}=5$ containers

$p=0.01$ ), but larvae exposed to urchins did not differ in length from controls or from those exposed to green crab cue (Bonferroni post hoc tests; $p>0.1$ ). Despite these differences in larval length at hatching, larval time to hatching was not significantly affected by maternal size or cue type (Table 2C, Fig. 6).

\section{Egg capsule morphometrics}

Large snails laid both taller and wider capsules than small snails, and both snail size and cue type 
Table 2. Two-way ANOVAs on egg size and larval development. Snail size, cue type, and their interaction were modeled as fixed effects. Container was modeled as a random effect. Significant effects $(p<0.016)$ are listed in bold

\begin{tabular}{|lcccc|}
\hline Dependent variable & Factor & df & $F$ & $\mathrm{p}$ \\
\hline (A) Egg size & Size & 1,24 & 5.347 & 0.029 \\
& Cue & 2,24 & 0.398 & 0.398 \\
(B) Larval size & Size $\times$ Cue & 2,24 & 1.938 & 0.165 \\
& Size & 1,23 & 3.459 & 0.076 \\
(C) Time to hatching & Cue & $\mathbf{2 , 2 3}$ & $\mathbf{5 . 6 3 9}$ & $\mathbf{0 . 0 1 0}$ \\
& Size $\times$ Cue & 2,23 & 0.686 & 0.513 \\
& Size & 1,22 & 0.005 & 0.943 \\
& Cue & 2,22 & 1.562 & 0.232 \\
& Size $\times$ Cue & 2,22 & 1.565 & 0.231 \\
\hline
\end{tabular}
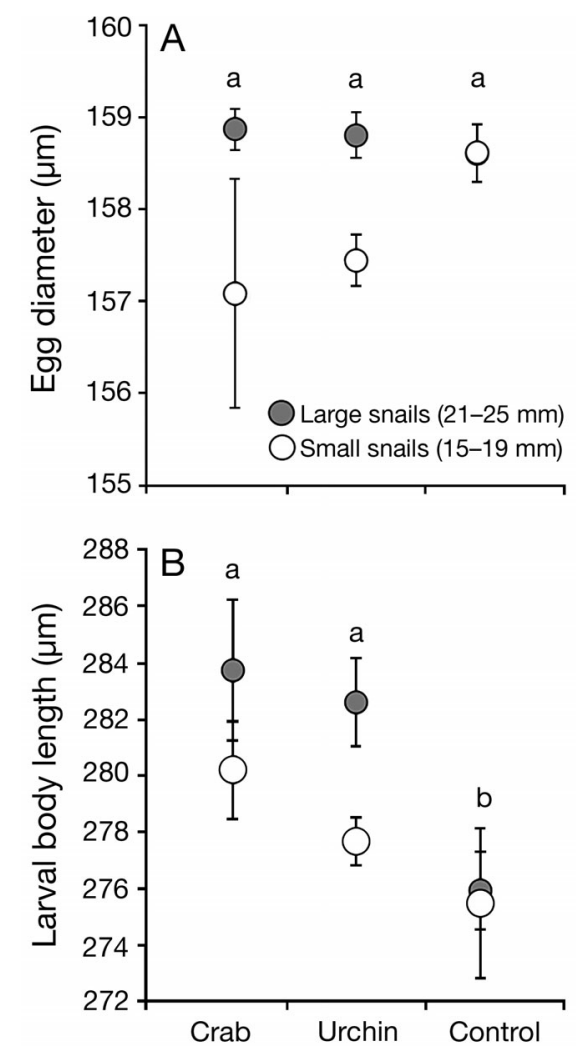

Fig. 5. (A) Egg diameter and (B) larval body length versus cue treatment. Note that dots are overlapping in (A) control. All circles represent means $\pm \mathrm{SE}$ for $\mathrm{N}=5$ containers. Different letters above symbols indicate significant differences among treatments

significantly affected the ratio of spine length to capsule height (Table 3, Fig. 7). Small snails had a significantly higher ratio than large snails, i.e. small snails lay capsules with longer spines relative to capsule size than do large snails (Fig. 7C). When exposed to green crab cue, the ratio of spine length to height

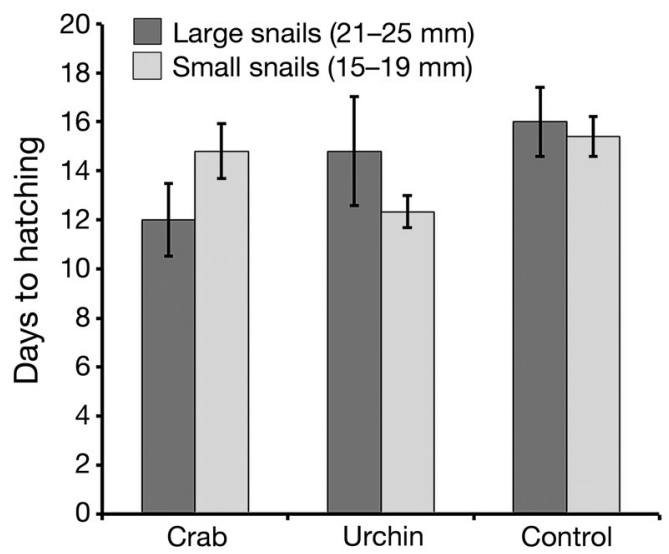

Fig. 6. Time to hatching, in days, versus cue treatment. All bars represent means $\pm \mathrm{SE}$ for $\mathrm{N}=5$ containers

increased by $30.6 \%$ in comparison to controls (Fig. $7 C_{\text {; }}$ Bonferroni post hoc test; $\mathrm{p}<0.001$ ). In snails exposed to urchins, the ratio of spine length to height was not significantly different from controls (Bonferroni post hoc test; $p>0.9$ ), but was significantly different from snails exposed to crabs (Bonferroni post hoc test $; \mathrm{p}=0.001$ ). These results suggest that for both large and small snails spine length increases as a response to predator cue.

\section{Effect of capsule morphology on predator deterrence}

The result that spine length increases in the presence of green crabs verified observations from previous work in our lab using hermit crabs (A. Santoni \& J. D. Allen unpubl. data). We initially tested whether this induced response might serve an adaptive function by observing whether hermit

Table 3. Two-way ANOVAs on egg capsule morphometrics. Snail size, cue type, and their interaction were modeled as fixed effects. Container number was modeled as a random effect. Significant effects $(p<0.016)$ are listed in bold

\begin{tabular}{|ccccc|}
\hline Dependent variable & Factor & df & $F$ & $\mathrm{p}$ \\
\hline (A) Capsule height & Size & $\mathbf{1 , 2 4}$ & $\mathbf{1 3 1 . 6 2 0}$ & $\mathbf{0 . 0 0 1}$ \\
& Cue & 2,24 & 0.566 & 0.575 \\
& Size $\times$ Cue & 2,24 & 3.027 & 0.067 \\
(B) Capsule width & Size & $\mathbf{1 , 2 4}$ & $\mathbf{1 8 6 . 2 0 0}$ & $\mathbf{0 . 0 0 1}$ \\
& Cue & 2,24 & 2.425 & 0.110 \\
(C) Spine & Size $\times$ Cue & 2,24 & 4.176 & 0.028 \\
length:height & Size & $\mathbf{1 , 2 4}$ & $\mathbf{1 2 . 7 9 3}$ & $\mathbf{0 . 0 0 2}$ \\
& Cue & $\mathbf{2 , 2 4}$ & $\mathbf{1 5 . 0 9 2}$ & $\mathbf{0 . 0 0 1}$ \\
& Size $\times$ Cue & 2,24 & 2.175 & 0.135 \\
\hline
\end{tabular}



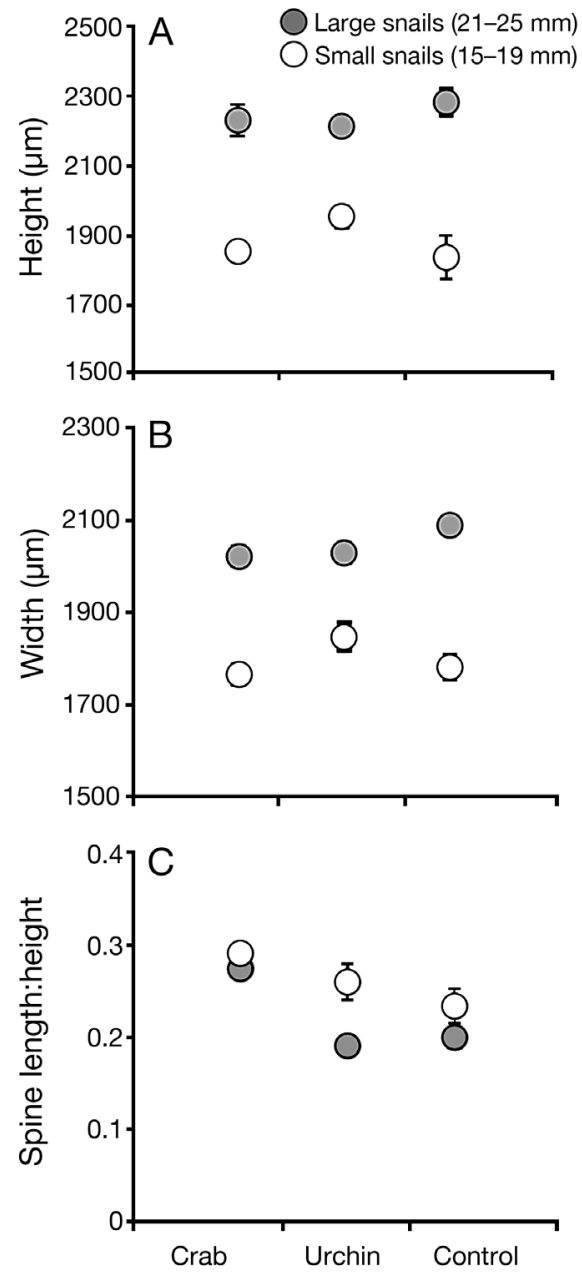

Fig. 7. Egg capsule morphometric measurements. (A) Capsule height, (B) capsule width and (C) ratio of capsule spine length to capsule height are plotted versus cue treatment. All circles represent means $\pm \mathrm{SE}$ for $\mathrm{N}=5$ containers. Error bars are not visible for some data points as they are smaller than the size of the symbols

crabs, green crabs, and green sea urchins would feed on long-spined, free-floating capsules in the lab. In nearly all observed instances of predation by hermit crabs and green crabs, egg capsules were sliced open near the capsule base, with all eggs removed. Capsules were rarely opened near the capsule plug, where elongated spines were located. These capsule predation trials suggested that hermit crabs selectively prey upon egg capsules on the basis of spine length. However, green crabs did not show selectivity, consuming all available capsules within a short period of time, while green urchins never consumed any capsules. Based on this result, only hermit crabs were used in further tests of the deterrent properties of spinelength.
Hermit crabs fed preferentially on short-spined capsules in 7 of 10 trials (Fig. 8). A HosmerLemeshow test of this logistic regression model was non-significant $(p=0.738)$, suggesting a significant fit of the model to the data. However, the relatively small sample size (20 capsules in each of 10 trials) limited the ability of this model to accurately predict predation to only $67 \%$ of all cases. Reported in Table $4, \operatorname{Exp}(\beta)$ is an odds ratio, the value of which corresponds to the likelihood of an event (predation) occurring given a change in one unit of the independent variable (e.g. spine length). The logistic regression model predicts that for every $1 \mu \mathrm{m}$ increase in spine length, the likelihood of capsule predation declines by $0.2 \%$ (Table 4 ). In contrast, the likelihood of predation was not driven by the trial number, position, height, or width of capsules.

We also sought to detect evidence of the benefit of longer spines in the field. We found that capsules that had been exposed to predation for longer, estimated from the stage of capsular development, differed significantly in their morphology from newer capsules (Fig. 9A-D). In particular, we found that older capsules did not differ in height (1-way ANOVA; $F_{2,90}=$ $2.736 ; \mathrm{p}=0.070$ ) but did differ in width (1-way ANOVA; $F_{2,90}=4.555 ; \mathrm{p}=0.013$ ). Hatched capsules were significantly narrower than capsules containing veligers, while veliger-containing capsules and embryo-containing capsules did not differ (Bonferroni post hoc test $\mathrm{p}=0.010$ and $\mathrm{p}=0.356$ respec-

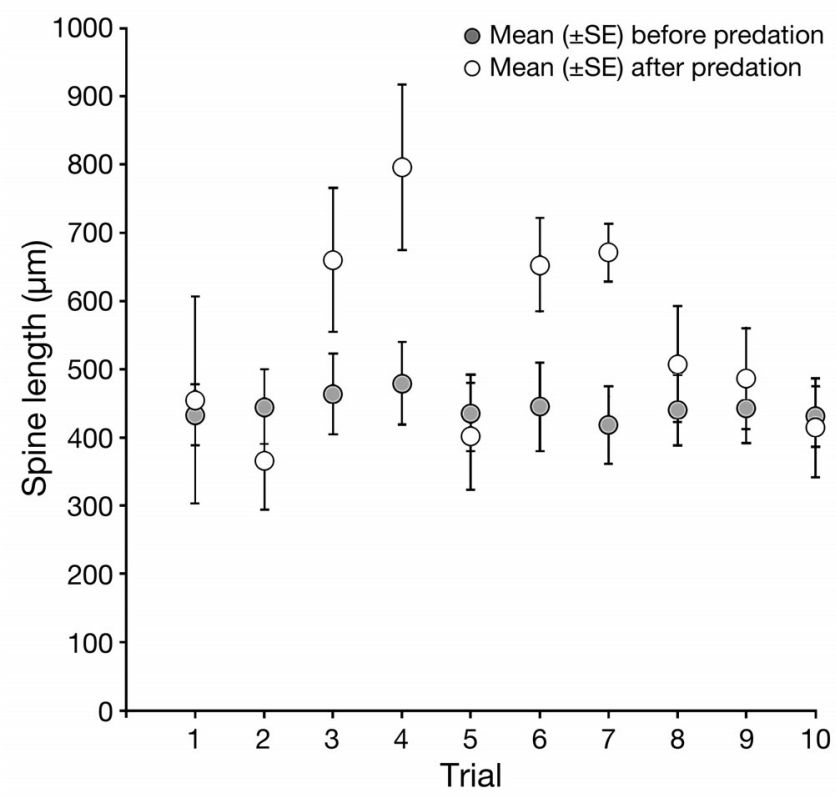

Fig. 8. Results of predation trials, plotting spine length before and after exposure to hermit crab predation. $\mathrm{N}=20$ capsules per trial 
Table 4. Logistic regression analysis of the effects of trial, position, capsule height, capsule width, and capsule spine length on capsule presence. Significant effects $(p<0.05)$ are listed in bold

\begin{tabular}{|lccc|}
\hline Predictor & $\beta$ & Sig. & $\operatorname{Exp}(\beta)$ \\
\hline Trial \# & -0.012 & 0.828 & 0.988 \\
Position & -0.007 & 0.800 & 0.993 \\
Height & -0.001 & 0.217 & 0.999 \\
Width & 0.000 & 0.791 & 1.000 \\
Spine length & $\mathbf{- 0 . 0 0 2}$ & $\mathbf{0 . 0 1 1}$ & $\mathbf{0 . 9 9 8}$ \\
\hline
\end{tabular}

tively). The morphological difference in width is likely due to the stretching of the capsule wall by growing veligers and was not a focus of our study. Both absolute spine length (1-way ANOVA; $F_{2,90}=$
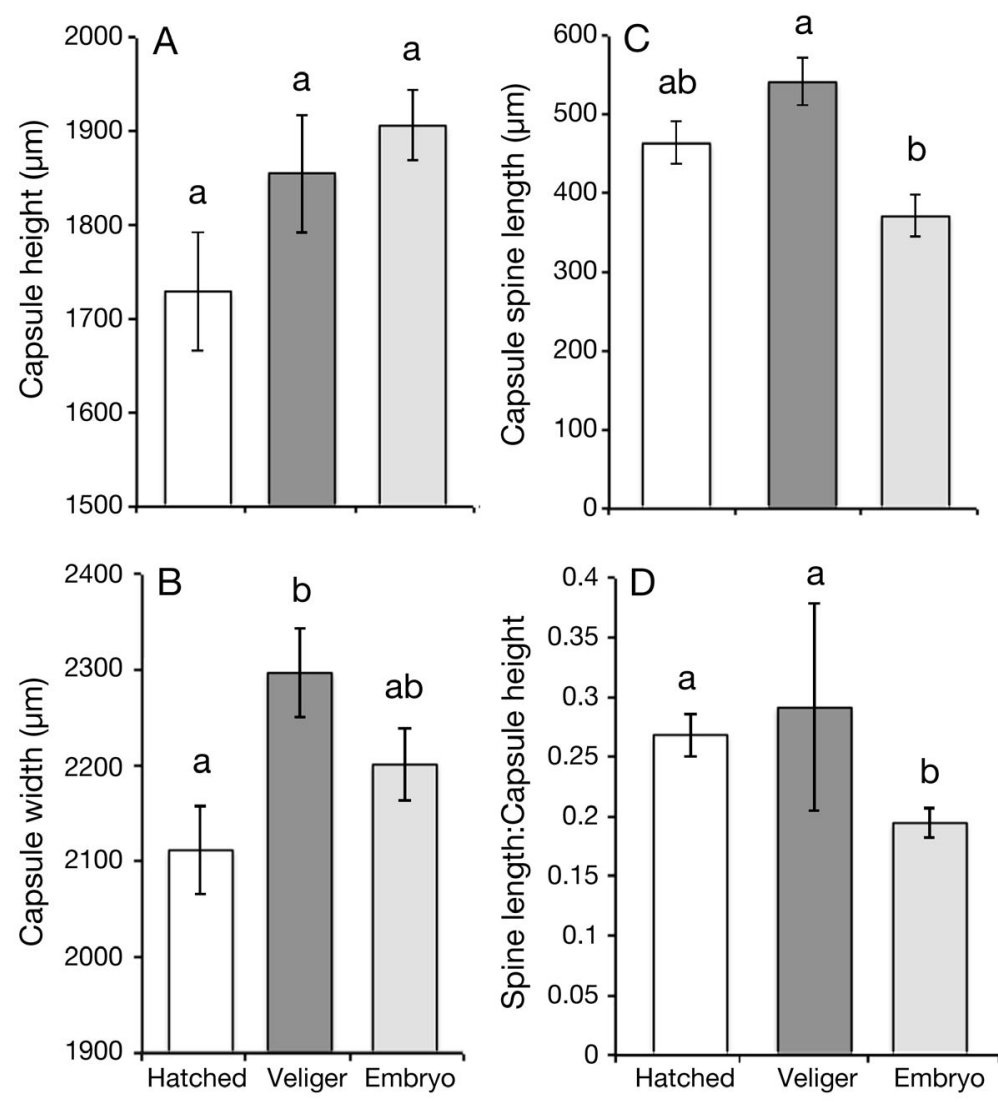

Fig. 9. Morphometrics of field-collected egg capsules, plotted against developmental stage. (A) Capsule height, (B) width, (C) spine length, and (D) ratio of spine length to capsule height for each of 3 developmental stages. 'Hatched' bars (white) represent otherwise intact capsules that were missing capsule plugs and were assumed to represent successful hatching events. 'Veliger' bars (dark gray) represent capsules containing late stage, swimming veliger larvae. 'Embryo' bars (light gray) represent capsules containing embryonic mud snails that had not developed any of the morphological characteristics (eye spots, lobes, etc.) characteristic of a veliger larva. All bars represent means $\pm \mathrm{SE}$ for $\mathrm{N}=30$ capsules. Different letters above symbols indicate significant differences among treatments
9.555; $\mathrm{p}<0.001$ ) and the ratio of spine length to capsule height varied significantly with the stage of capsular development (1-way ANOVA; $F_{2,90}=12.287$; $\mathrm{p}<0.001)$. Capsules containing embryos had shorter absolute spine lengths than did capsules containing veligers (Fig. 9C; Bonferroni post hoc test $\mathrm{p}<0.001$ ), while no significant differences were found between capsules containing embryos and hatched capsules (Bonferroni post hoc test; p $=0.059$ ) or between hatched capsules and capsules containing veligers (Bonferroni post hoc test; $\mathrm{p}=0.154$ ). When spine length was considered relative to capsule height (Fig. 9D), we found that embryo-containing capsules had significantly shorter spines than did veligercontaining (Bonferroni post hoc test; p < 0.001) and hatched capsules (Bonferroni post hoc test; $\mathrm{p}=$ 0.001). No differences were detected in the relative spine lengths of hatched capsules and veliger-containing capsules (Bonferroni post hoc test; $\mathrm{p}>0.5$ ).

\section{DISCUSSION}

Our field observations and laboratory manipulations suggest that mud snails both detect and respond to the presence of predators that they commonly encounter in soft-sediment habitats. In a laboratory setting, we were able to induce the production of longer spines in the presence of crab predators and demonstrate a potentially adaptive value for these longer spines by showing that they reduce consumption by hermit crab predators. In addition, we found that, in the field, successful egg capsules have longer spines, and that mud snails adjust their distribution in a manner consistent with the avoidance of high density crab habitats. Finally, we found significant maternal effects, largely driven by differences in maternal size, on a variety of reproductive characteristics. Perhaps most surprisingly, snails showed a consistent interaction between maternal size and their responses to the presence of green sea urchins, our intended metabolic control. These unexpected results highlight the importance of including additional types of controls/cues in experiments examining phenotypically plastic responses in aquatic systems. 


\section{Intertidal distribution}

Our study of the intertidal distribution of mud snails demonstrates that mud snail density decreases with increasing density of green crabs, suggesting that mud snails may preferentially position themselves so as to reduce the threat of predation. In general, snails living at the highest densities, found farthest from the green crab habitat, had the smallest body size. Large snails tended to be found lower in the intertidal, where green crabs are most likely to forage at low tides, but possess shells that are difficult for crabs and other predators to crush (Tucker et al. 1997). In other intertidal gastropods, lower distributional limits are set by predatory crabs (Feare 1970), and therefore the size-specific distribution we observed may be an adaptive response by small snails to mitigate predation pressure. However, given the relatively small area of snail habitat at this site, it remains to be seen whether this spatial assortment is indeed an adaptive response by snails to predation pressure or is due to some other ecological factor that is correlated with either crab abundance or snail density (e.g. competition).

The correlation between snail size and sex could be explained by several possible mechanisms. Sexbased physiological differences in this species may allow females to grow to larger sizes than males. Alternatively, females may simply grow at a faster rate than males, given that female mud snails appear to have enhanced foraging capabilities during the reproductive season (Curtis 1979). Finally, although other populations of mud snails have been described as dioecious (Smith 1980), mud snails may be sequential hermaphrodites, with males undergoing a switch in gender with increasing size. Hermaphroditism occurs in $3 \%$ of all prosobranch gastropod species (Heller 1993) and the sigmoidal relationship between body size and sex in our data suggests a size-dependent switch in sex from male to female that occurs around $20 \mathrm{~mm}$. While sex determination in mud snails can be obscured by environmentallyinduced imposex (i.e. the development of male sexorgans in females; Smith 1971, Jenner 1979) or the presence of castrating parasites (Sullivan et al. 1985), neither of those phenomena explain the size-specific sex ratios we describe here. Snail sex is outwardly cryptic and generally requires the destruction of the shell, but future studies using non-destructive techniques for sexing snails (e.g. Curtis \& Hurd 1983) may be able to distinguish among these hypotheses. For the current study, it is clear that there were more females present in the large snail size treatments than in the small, simply due to the shifts in sex ratio describe above. Perhaps some of the differences in reproductive output are not directly attributable to size differences but rather due to differences in female condition (due to poor diet etc.) that led to a small size at sexual maturity.

\section{Maternal size effects}

As predicted, large snails, whose energetic reserves are almost certainly greater than small snails, produced more offspring. However, contrary to our expectations, large snails did not lay more capsules, but rather deposited more eggs per capsule. This pattern of increasing egg density with female size has regularly been demonstrated in other gastropod species (e.g. Perron \& Corpus 1982, Chaparro \& Flores 2002). Further, the overall increase in reproductive output (i.e. egg density $\times$ capsule number) that we describe is consistent with the positive correlation between egg number and female body size found in gastropods and a number of other marine taxa (Barnes \& Barnes 1968, Ito 1997). Why snails do not lay more capsules is unclear; although laying fewer capsules may decrease the likelihood of their discovery by benthic predators, there may be metabolic costs to developing embryos when laying more eggs per capsule (Strathmann \& Chaffee 1984).

Contrary to our expectations, egg size and hatching time did not vary significantly in response to predator presence. However, larvae exposed to green crab cue grew to a larger size before hatching ( 2\% longer). While there are potential benefits to a larger size at hatching (e.g. a larger velum for increased feeding success, larger size at, and earlier time to settlement and sexual maturity; Perron 1981b, Marshall \& Keough 2003, Emlet \& Sadro 2006), we did not measure post-larval benefits of increased hatching size in Ilyanassa obsoleta. Alternatively, larger size may come at a cost, possibly one that is paid in larval form or function that we did not measure in our study. Regardless, these data suggest that larval hatching parameters such as size at hatching are plastic and responsive to environmental conditions including predator presence, as has been shown in a wide array of taxa (Warkentin 2011). The result that size at hatching, but not time to hatching varied with predator presence contrasts with a prior study on hatching plasticity in marine gastropods which found that snails delayed hatching in response to predators, but did not vary in size (Miner et al. 2010). The discrepancy in these results may be underlain by differ- 
ences in life histories between the direct-developing snails studied by Miner et al. (2010) and the mixed life history (encapsulation followed by a feeding larval stage) of the mud snails described here. Future studies examining hatching plasticity in marine snails with a variety of life history patterns are clearly warranted to clarify these results.

\section{Maternal size effects and predator cue}

It is unclear whether the positive relationship between capsule size and maternal size is simply physiological, with larger mothers having larger reproductive tracts and thus forming larger capsules and eggs (as in Conus pennaceus, Perron \& Corpus 1982), or whether the investment of more eggs per capsule by larger mothers concomitantly expands the volume of each egg capsule. Given the ease with which predatory crabs seem to be able to consume capsules of all sizes, it is unclear whether there are benefits of increasing capsule size. In contrast, an increase in capsule size could result in oxygen limitation for larvae developing in the center of the capsule, which is a potentially significant cost (e.g. Cohen \& Strathmann 1996, Woods \& Podolsky 2007).

Our finding that capsule spine length increases in the presence of predators makes this study one of only a few to demonstrate maternally induced defenses in egg capsules. Previous descriptions of egg capsule defenses include changes in the thickness of the capsule wall or the deposition of chemical deterrents, rather than the elongation of defensive spines (e.g. Rawlings 1994, Johnson \& Willows 1999). Although hermit crabs appear to be able to prey upon egg capsules of all spine lengths, preferences for small-spined egg capsules may be due to increased handling time associated with long-spined capsules. When attempting to remove capsules from eelgrass, hermit crabs primarily position themselves above an egg capsule before attempting to pull the capsule from the substrate. Because capsule spines project from the apex of each capsule, they may deter hermit crabs from positioning themselves directly above a capsule, thus increasing handling time and the potential for foraging hermit crabs to be preyed upon (Elner \& Hughes 1978, Boulding 1984, SanchezSalazar et al. 1987).

While the spine-length response was induced by green crab cues in our experiments, we chose to test its adaptive function with hermit crabs. Pilot studies had demonstrated that, when exposed to heightened hermit crab cue, mud snails lay egg capsules with similarly elongated spines (A. Santoni \& J. D. Allen unpubl. results). When we tested the preferences of both hermit crabs and green crabs for capsules with different-sized spines, only the hermit crab appeared to forage selectively. Thus, the induced response to green crab cues, despite the inability of spines to mitigate green crab predation, may be the result of the inability of mud snails to distinguish the differences between the cues produced by green crabs and hermit crabs. Other intertidal gastropods have been shown to be able to distinguish between predatory and non-predatory crabs (Marko \& Palmer 1991), but since both hermit crabs and green crabs are predators of egg capsules (Brenchley 1982), selection for distinguishing species-specific cues may be weak.

\section{Maternal size effects and urchin cue}

We predicted that smaller snails would reduce reproductive output more relative to large snails in the presence of predator cue, which they did $(33 \%$ reduction in predator cue treatment vs. $20 \%$ reduction in controls). However, we did not expect a sizespecific effect on reproductive output in the presence of urchin cue ( $70 \%$ reduction). Strongylocentrotus droebachiensis was originally selected as a metabolic control because it does not typically share a habitat with Ilyanassa obsoleta, and is primarily herbivorous (Himmelman \& Steele 1971). Further, preliminary laboratory predation trials exposing large and small adult mud snails to the variegated urchin Lytechinus variegatus and $S$. droebachiensis resulted in no predation-related mortality (S. Abdel-Raheem, L. Boyle, \& J. D. Allen unpubl. obs.).

One explanation for our unexpected results is that green urchins may have historically preyed upon adult mud snails or their egg capsules, and the responses observed here could be the result of evolved responses to past predation pressures. Mud snails have been driven from their historic range due to competition with periwinkles (Brenchley \& Carlton 1983) and urchin populations have been decimated by overfishing (Steneck et al. 2004). Therefore, the present distribution of mud snails and urchins may not reflect historical distributions where these species may have overlapped and interacted. In Cobscook Bay, ME, urchins have recently been observed at high densities in the subtidal, soft sediment systems dominated by mud snails (L. Harris pers. obs.), perhaps reflecting a now-rare remnant of past opportunities for ecological interactions. Alternatively, the generalist nature of urchin predation/herbivory 
could mean that egg capsules are consumed only when urchins are grazing the algae that capsules are laid on. If true, then capsule consumption may simply be a byproduct of urchin herbivory.

It also seems feasible that the plasticity observed in this study may be the result of snails responding to similar kairomones between urchins and sea stars such as Asterias forbesi, a known predator on mud snails in the lab (Peterson 1979) and the field (M. Luckenbach pers. obs.). However, because the responses in question were only exhibited by small snails, it seems unlikely that this reflects a response to the threat of predation by sea stars, which are not size-specific in their predation on mud snails. Sea stars prey upon snails by inserting their stomach into the shell aperture and consistently consume the largest mud snails offered under laboratory conditions (A. Santoni \& J. D. Allen unpubl. results).

While we initially felt confident that Strongylocentrotus droebachiensis do not prey upon mud snail egg capsules, there is at least one recorded observation of $S$. droebachiensis feeding on the egg capsules of a gastropod. Similar to Ilyanassa obsoleta, the Pribilof whelk Neptunea pribiloffensis lays large benthic egg masses with encapsulated embryos. During intracapsular development, embryos are frequently preyed upon by S. droebachiensis (Shimek 1981). Although there are presently no observations of green urchins preying upon mud snail egg capsules in the laboratory or the field, we have observed intense predation of mud snail egg capsules by another urchin, Lytechinus variegatus. Taken together with the historical overlap of these species, these observations suggest that green urchins may currently feed on egg capsules in the field and/or may have been a predator on them in the recent past. If so, green urchins were a poor choice for a metabolic control, and should instead be treated as a second predator in this study.

Finally, although we did not test the effects of multiple cues simultaneously (i.e. crab and urchin), our results support the recent recognition that prey may frequently assess and respond to cues from a variety of sources in the benthic community at the same time (Freeman 2007, Bourdeau 2009, Freeman et al. 2009). The data presented here amplify the recognition that multiple simultaneous cues can modify phenotypically plastic responses by suggesting that the status of the cue receiver also modifies the nature of the response. If we had only examined the responses of large snails to our cue treatments, we would have overlooked the strong suppressive effect of urchins on snail reproductive output.

\section{CONCLUSIONS}

Although maternal size is well studied for its effects on a number of reproductive parameters, such as the increased reproductive output described here, there are relatively few studies detailing how maternal size influences reproductive responses in the presence of predators. We found that maternal size interacted most strongly with the presence of green urchins, which are not known to consume snails or their capsules. Why these responses were seen in small but not large snails is unclear, and may be explained by either consumptive or non-consumptive effects. Independently, female size and the presence of cues from 2 co-occurring species also had strong effects on mud snail reproductive output and capsule morphology, suggesting that the ecological success of this species in both native and introduced habitats may be due, in part, to the ability of mud snails to adjust reproduction in response to environmental cues. Altogether, the results presented here suggest that maternal effects are a context-dependent and multivariate phenomenon and that both ecological and intrinsic factors can modify the role that maternal effects play in the early development of offspring.

Acknowledgements. This research was funded by grant number J-967 from the Jeffress Memorial Trust to J.D.A. D.B.S. was supported by summer fellowships from a Howard Hughes Medical Institute grant through the Undergraduate Biological Sciences Education Program to the College of William and Mary. We thank A. Johnson, R. Armstrong and Bowdoin College for providing laboratory space at the Bowdoin College Marine Laboratory during the completion of this work. F. Armstrong, H. Blackburn, K. Hoolihan, J. Salyers, and C. White provided assistance with data collection in the laboratory and the field. S. Abdel-Raheem and L. Boyle conducted trials on urchin feeding on mud snails. J. Pechenik provided helpful suggestions that resulted in our collection of field data on capsule spine lengths. M. Pizer provided valuable feedback on an earlier draft of this manuscript. Contribution \#1 from the Bowdoin Marine Laboratory.

\section{LITERATURE CITED}

Agrawal AA, Laforsch C, Tollrian R (1999) Transgenerational induction of defences in animals and plants. Nature 401:60-63

Allen JD, McAlister JS (2007) Testing rates of planktonic versus benthic predation in the field. J Exp Mar Biol Ecol 347:77-87

Appleton RD, Palmer AR (1988) Water-borne stimuli released by crabs and damaged prey induce more predator-resistant shells in a marine gastropod. Proc Natl Acad Sci USA 85:4387-4391

> Banks PB, Powell F (2004) Does maternal condition or predation risk influence small mammal population dynamics? Oikos 106:176-184 
Barnes H, Barnes M (1968) Egg numbers, metabolic efficiency of egg production and fecundity; local and regional variations in a number of common cirripedes. J Exp Mar Biol Ecol 2:135-153

Bernardo J (1996) Maternal effects in animal ecology. Am Zool 36:83-105

Boulding EG (1984) Crab-resistant features of shells of burrowing bivalves: decreasing vulnerability by increasing handling time. J Exp Mar Biol Ecol 76:201-223

Bourdeau PE (2009) Prioritized phenotypic responses to combined predators in a marine snail. Ecology 90: 1659-1669

> Brenchley GA (1982) Predation on encapsulated larvae by adults: effects of introduced species on the gastropod Ilyanassa obsoleta. Mar Ecol Prog Ser 9:255-262

Brenchley GA, Carlton JT (1983) Competitive displacement of native mud snails by introduced periwinkles in the New England intertidal zone. Biol Bull (Woods Hole) 165: 543-558

> Callaway RM, Pennings SC, Richards CL (2003) Phenotypic plasticity and interactions among plants. Ecology 84: 1115-1128

> Chaparro OR, Flores ML (2002) Reproductive output of Crepidula fecunda females: distribution of energy in the production of gametes and capsules walls. NZ J Mar Freshw Res 36:661-673

> Charmantier A, McCleery RH, Cole LR, Perrins C, Kruuk LEB, Sheldon BC (2008) Adaptive phenotypic plasticity in response to climate change in a wild bird population. Science 320:800-803

> Chatzinikolaou E, Richardson CA (2010) Parental size and environmental conditions affect egg capsule production by Nassarius reticulatus (Linnaeus 1758) (Gastropoda: Nassariidae). J Exp Mar Biol Ecol 390:14-21

> Cohen SC, Strathmann RR (1996) Embryos at the edge of tolerance: effects of environment and structure of egg masses on supply of oxygen to embryos. Biol Bull (Woods Hole) 190:8-15

Corkum LD, Ciborowski JJH, Poulin RG (1997) Effects of emergence date and maternal size on egg development and sizes of eggs and first-instar nymphs of a semelparous aquatic insect. Oecologia 111:69-75

> Cranford PJ (1988) Behaviour and ecological importance of a mud snail (Ilyanassa obsoleta) population in a temperate macrotidal estuary. Can J Zool 66:459-466

> Curtis LA (1979) On the broad nutritional requirements of the mud snail, Ilyanassa (Nassarius) obsoleta (Say), and its polytrophic role in the food web. J Exp Mar Biol Ecol 41:289-297

> Curtis LA (1997) Ilyanassa obsoleta (Gastropoda) as a host for trematodes in Delaware estuaries. J Parasitol 83: 793-803

> Curtis LA, Hurd LE (1983) Age, sex, and parasites: spatial heterogeneity in a sandflat population of Ilyanassa obsoleta. Ecology 64:819-828

$>$ Elner RW, Hughes RN (1978) Energy maximization in the diet of the shore crab, Carcinus maenas. J Anim Ecol 47: 103-116

Emlet RB, Sadro SS (2006) Linking stages of life history: how larval quality translates into juvenile performance for an intertidal barnacle (Balanus glandula). Integr Comp Biol 46:334-346

Feare CJ (1970) Aspects of the ecology of an exposed shore population of dogwhelks Nucella lapillus (L.). Oecologia $5: 1-18$
Fell PE, Olmstead NC, Carlson E, Jacob W, Hitchcock D, Silber G (1982) Distribution and abundance of macroinvertebrates on certain Connecticut tidal marshes, with emphasis on dominant molluscs. Estuaries 5:234-239

> Freeman AS (2007) Specificity of induced defenses in Mytilus edulis and asymmetrical predator deterrence. Mar Ecol Prog Ser 334:145-153

Freeman AS, Meszaros J, Byers JE (2009) Poor phenotypic integration of blue mussel inducible defenses in environments with multiple predators. Oikos 118:758-766

Gosner KL (1978) A field guide to the Atlantic seashore. Houghton Mifflin Company, Boston, MA

Heller J (1993) Hermaphroditism in molluscs. Biol J Linn Soc 48:19-42

> Himmelman JH, Steele DH (1971) Foods and predators of the green sea urchin Strongylocentrotus droebachiensis in Newfoundland waters. Mar Biol 9:315-322

> Ito K (1997) Egg-size and -number variations related to maternal size and age, and the relationship between egg size and larval characteristics in an annual marine gastropod, Haloa japonica (Opisthobranchia; Cephalaspidea). Mar Ecol Prog Ser 152:187-195

> Jenner MG (1979) Pseudohermaphroditism in Ilyanassa obsoleta (Mollusca: Neogastropoda). Science 205: 1407-1409

Johnson PM, Willows AOD (1999) Defense in sea hares (Gastropoda, Opisthobranchia, Anaspidea): multiple layers of protection from egg to adult. Mar Freshwat Behav Physiol 32:147-180

> Marko PB, Palmer AR (1991) Responses of a rocky shore gastropod to the effluents of predatory and non-predatory crabs: avoidance and attraction. Biol Bull (Woods Hole) 181:363-370

- Marshall DJ (2008) Transgenerational plasticity in the sea: context-dependent maternal effects across the life history. Ecology 89:418-427

Marshall DJ, Keough MJ (2003) Effects of settler size and density on early post-settlement survival of Ciona intestinalis in the field. Mar Ecol Prog Ser 259:139-144

Marshall DJ, Keough MJ (2004a) Variable effects of larval size on post-metamorphic performance in the field. Mar Ecol Prog Ser 279:73-80

> Marshall DJ, Keough MJ (2004b) When the going gets rough: effect of maternal size manipulation on larval quality. Mar Ecol Prog Ser 272:301-305

Marshall DJ, Morgan SG (2011) Ecological and evolutionary consequences of linked life-history stages in the sea. Curr Biol 21:R718-R725

Marshall DJ, Uller T (2007) When is a maternal effect adaptive? Oikos 116:1957-1963

> Miner BG, Donovan DA, Andrews KE (2010) Should I stay or should I go: predator- and conspecific-induced hatching in a marine snail. Oecologia 163:69-78

Palmer AR (1982) Growth in marine gastropods: a nondestructive technique for independently measuring shell and body weight. Malacologia 23:63-73

Pechenik JA (1975) The escape of veligers from the egg capsules of Nassarius obsoletus and Nassarius trivittatus (Gastropoda, Prosobranchia). Biol Bull (Woods Hole) 149: 580-589

> Pechenik JA (2006) Larval experience and latent effects metamorphosis is not a new beginning. Integr Comp Biol 46:323-333

Pechenik JA, Wendt DE, Jarrett JN (1998) Metamorphosis is not a new beginning. Bioscience 48:901-910 
Perron FE (1981a) Larval biology of 6 species of the genus Conus (gastropoda: Toxoglossa) in Hawaii, USA. Mar Biol 61:215-220

Perron FE (1981b) Larval growth and metamorphosis of Conus (Gastropoda: Toxoglossa) in Hawaii. Pac Sci 35: 25-38

Perron FE, Corpus GC (1982) Costs of parental care in the gastropod Conus pennaceus: age specific changes and physical constraints. Oecologia 55:319-324

> Peterson CH (1979) The importance of predation and competition in organizing the intertidal epifaunal communities of Barnegat Inlet, New Jersey. Oecologia 39:1-24

Pomeroy PP, Fedak MA, Rothery P, Anderson S (1999) Consequences of maternal size for reproductive expenditure and pupping success of grey seals at North Rona, Scotland. J Anim Ecol 68:235-253

Race MS (1982) Competitive displacement and predation between introduced and native mud snails. Oecologia 54:337-347

Rawlings TA (1990) Associations between egg capsule morphology and predation among populations of the marine gastropod, Nucella emarginata. Biol Bull (Woods Hole) 179:312-325

Rawlings TA (1994) Encapsulation of eggs by marine gastropods: effect of variation in capsule form on the vulnerability of embryos to predation. Evolution 48:1301-1313

Ritchie H, Marshall DJ (2013) Fertilisation is not a new beginning: sperm environment affects offspring developmental success. J Exp Biol 216:3104-3109

Rittschof D, Sawardecker P, Petry C (2002) Chemical mediation of egg capsule deposition by mud snails. J Chem Ecol 28:2257-2269

Rollinson N, Hutchings JA (2011) Body size-specific maternal effects on the offspring environment shape juvenile phenotypes in Atlantic salmon. Oecologia 166:889-898

Sanchez-Salazar ME, Griffiths CL, Seed R (1987) The effect of size and temperature on the predation of cockles Cerastoderma edule (L.) by the shore crab Carcinus maenas (L.). J Exp Mar Biol Ecol 111:181-193

Scheltema RS (1961) Metamorphosis of the veliger larvae of Nassarius obsoletus (Gastropoda) in response to bottom sediment. Biol Bull (Woods Hole) 120:92-109

Scheltema RS (1962) Pelagic larvae of New England intertidal gastropods I. Nassarius obsoletus Say and Nassarius vibex Say. Trans Am Microsc Soc 81:1-11

Shimek RL (1981) Neptunea pribiloffensis (Dall, 1919) and Tealia crassicornis (Muller 1776): on a snail's use of babysitters. Veliger 24:62-66

Smith BS (1971) Sexuality in the American mud snail, Nas-

Editorial responsibility: James McClintock, Birmingham, Alabama, USA sarius obsoletus. Proc Malacol Soc Lond 39:377-378

Smith BS (1980) The estuarine mud snail, Nassarius obsoletus: abnormalities in the reproductive system. J Molluscan Stud 46:247-256

Spight TM, Emlen J (1976) Clutch sizes of 2 marine snails with a changing food supply. Ecology 57:1162-1178

Steneck RS, Vavrinec J, Leland AV (2004) Accelerating trophic-level dysfunction in kelp forest ecosystems of the western North Atlantic. Ecosystems 7:323-332

Storm JJ, Lima SL (2010) Mothers forewarn offspring about predators: a transgenerational maternal effect on behavior. Am Nat 175:382-390

Strathmann RR, Chaffee C (1984) Constraints on egg masses. II. Effect of spacing, size, and number of eggs on ventilation of masses of embryos in jelly, adherent groups, or thin- walled capsules. J Exp Mar Biol Ecol 84:85-93

Sullivan CH, Bonar DB (1984) Biochemical characterization of the hatching process of Ilyanassa obsoleta. J Exp Zool 229:223-234

Sullivan JT, Cheng TC, Howland KH (1985) Studies on parasitic castration: castration of Ilyanassa obsoleta (Mollusca: Gastropoda) by several marine trematodes. Trans Am Microsc Soc 104:154-171

Tollrian R (1995) Predator-induced morphological defenses: costs, life history shifts, and maternal effects in Daphnia pulex. Ecology 76:1691-1705

> Trussell GC (1996) Phenotypic plasticity in an intertidal snail: the role of a common crab predator. Evolution 50:448-454

Trussell GC, Smith LD (2000) Induced defenses in response to invading crab predator: An explanation of historical and geographic phenotypic change. Proc Natl Acad Sci USA 97:2123-2127

> Tucker AD, Yeomans SR, Gibbons JW (1997) Shell strength of mud snails (Ilyanassa obsoleta) may deter foraging by diamondback terrapins (Malaclemys terrapin). Am Midl Nat 138:224-229

- Uller T (2008) Developmental plasticity and the evolution of parental effects. Trends Ecol Evol 23:432-438

Vaughn D, Allen JD (2010) The peril of the plankton. Integr Comp Biol 50:552-570

> Warkentin KM (2011) Environmentally cued hatching across taxa: embryos respond to risk and opportunity. Integr Comp Biol 51:14-25

Wolf JB, Wade MJ (2009) What are maternal effects (and what are they not)? Philos Trans R Soc Lond B Biol Sci 364:1107-1115

Woods HA, Podolsky RD (2007) Photosynthesis drives oxygen levels in macrophyte- associated gastropod egg masses. Biol Bull (Woods Hole) 213:88-94

Submitted: June 24, 2013; Accepted: November 15, 2013 Proofs received from author(s): February 3, 2014 